\title{
Erosive tooth Wear in special Olympic athletes with intellectual disabilities
}

\author{
F. Marro ${ }^{1,5^{*}}$, C. Fernandez ${ }^{2}$, L. Martens ${ }^{1}$, W. Jacquet ${ }^{3,4}$ and L. Marks ${ }^{2}$
}

\begin{abstract}
Background: Special Olympics (SO) events represent an opportunity to obtain considerable information regarding intellectual disable (ID) patients. Studies done with SO data have shown an overview of the oral health status of these athletes; however, no information exists regarding the erosive tooth wear (ETW). Therefore, the aim of this study is to determine the presence and severity of ETW in athletes with ID who participated in the SO Belgium 2016.

Methods: The study population consisted in 232 athletes with ID who participated in the SO special smiles program, Belgium 2016. For analysis, the sample was divided in three groups: a) athletes with ID under the age of 25 not diagnosed with Down Syndrome (DS) $(n=174)$, b) athletes with DS under the age of $25(n=39)$ and c) athletes with DS from 25 and older ages $(n=58)$. Two calibrated dentists performed dental examinations using the Basic Erosive Wear Examination Index (BEWE). The BEWE sum $>0$ was used to determine prevalence of ETW. Severity was determined by two- indicators: 1) By risk levels (low, medium and high risk) proposed by the BEWE index, and 2) by the highest score reached per subject in at least one tooth (BEWE1, 2 or 3). Chi-square test and Mann-Whitney $U$ test were used to detect significant differences among different groups $(p<0.05)$.

Results: The prevalence of ETW for young athletes with ID was 51.14\%. Within these athletes, the DS group presented a significant higher mean BEWE sum (4.67, SD 5.64) and prevalence of ETW (69.2\%BEWE>0) when compared to athletes without DS (mean BEWE sum: 1.96, SD 3.47 and 46.3\% BEWE $>0 ; p<0.05$ ). Furthermore, a significantly higher percentage of athletes with DS were considered at high risk of ETW $(p<0.05)$.

Conclusions: As a conclusion, half of the young athletes with ID presented at least one affected surface with ETW. The recorded prevalence and severity of ETW for the younger group of athletes with DS was distinctly higher than the athletes with ID not having DS. This shows the need to generate knowledge in order to provide correct management and prevention of erosive tooth wear in populations with ID.
\end{abstract}

Keywords: Erosive tooth wear, Patients with intellectual disability, Down syndrome, Special Olympics athletes

\section{Background}

Erosive tooth wear (ETW), known as the chemicalmechanical process of tooth wear caused principally by extrinsic/intrinsic acids [1], has become a topic of concern for the dental community. The apparent increase in the prevalence of ETW and the current dietary habits involving a high intake of extrinsic acids are the reasons behind this concern [1, 2]. In 2015, the worldwide

\footnotetext{
*Correspondence: francisca.marro@ugent.be

'Department of Paediatric Dentistry, PaeCoMeDis research cluster, Ghent University, Ghent, Belgium

${ }^{5}$ Department Paediatric Dentistry \& Special Care Dentistry, Dental School, Faculty of Medicine and Health sciences, University Gent, Gent, Belgium Full list of author information is available at the end of the article
}

prevalence of ETW was estimated to be $30 \%$ for children and adolescents [3], and in Europe a multicentre investigation suggested that $57 \%$ of the young adults (18-35 years old) have at least one affected surface by ETW [4]. Up to date, several studies have investigated the prevalence of ETW among the general population; however, there is limited evidence regarding how this condition affects minority groups such as the people with Intellectual disabilities (ID) [5-7].

In the past few years, the Special Smiles program organized by the Special Olympics contest (SOSS) has become an important platform to investigate and evaluate the oral health status and treatment needs of a

(c) The Author(s). 2019 Open Access This article is distributed under the terms of the Creative Commons Attribution 4.0 International License (http://creativecommons.org/licenses/by/4.0/), which permits unrestricted use, distribution, and 
considerable number of patients with ID [8]. This program collects data of athletes with ID from all over the world in order to understand their treatment needs and improve their access to oral health care [9]. Numerous publications using SOSS data suggest that patients with ID participating in such contest have a higher prevalence of periodontal diseases, poorer oral hygiene and higher rates of untreated decay when compared with the general population $[8,10]$. Until now, several oral health parameters are included in the Special smiles screenings with much attention drawn in to the major oral health problems such as caries and periodontal diseases; however, other prevalent conditions affecting the oral health status have not been included.

Since the topic of ETW has become relevant over the past few years, it is highly important to include the study of this condition during SOSS events.

Therefore, the primary aim of the study was to include for the first time at SOSS event an examination of ETW in order to determine the prevalence and severity of ETW in a young group of athletes with ID (up to 25-yr-olds) participating in the SOSS, Belgium 2016. In addition, since one of the most prevalent syndromes presenting ID at SO events is Down Syndrome (DS), the secondary aim was to determine the same parameters on the entire group of athletes with Down syndrome (DS; all ages).

\section{Materials and methods}

\section{Ethical issues}

For this cross-sectional study, data were collected at the annual SO event held in May 2016 in La Louviere, Belgium. Ethical approval was obtained from the local ethical committee of the Ghent University Hospital according to the "ICH Good Clinical Practice" of the declaration of Helsinki (2016/0461). Participation consent from the athlete and/or the legal guardian was collected.

\section{Population}

All the young athletes with ID (up to age 25, age range 9-25) and the older group of athletes diagnosed with DS (age 26 and up, age range 26-62) who participated in the SOSS program, Belgium 2016, were included in this study. Exclusion criteria were subjects who declined participation when they registered for the screening.

\section{Calibration of the examiners}

Prior to the study, two examiners (FM and CF) were trained and calibrated during a period of two months against an experienced benchmark (LM) for the consistent diagnosing of ETW and the use of the BEWE index according to Bartlett et al. 2008 [11]. Intra-examiner reliability (acc. Landis and Koch) was substantial (0.78 for
FM and 0.88 for $\mathrm{CF}$ ) and the Inter-examiner reliability was 0.65 (unweight Cohen's kappa).

\section{Clinical examinations}

Intra-oral examinations were performed during the SOSS event. Standard illumination (LED head lamps) and sterile number 5 mouth mirrors were used to examine all surfaces of the permanent dentition. Before scoring, dental surfaces were dried using sterile compresses. Presence and severity of ETW lesions were recorded using the BEWE score criteria. According to this classification, every permanent tooth surface was examined and classified into 4 score criteria as follows: '0-' an indication for absence of ETW, '1-' an indication for initial loss of surface texture (visually detectable), ' 2 '\% - an indication for distinct defect of hard tissue loss with less than $50 \%$ of the surface area affected, and ' 3 ' - an indication for hard tissue loss equal or more than $50 \%$ of the surface area ("can also involve dentin).

The "BEWE sum" calculated per individual was the result of the sum of the highest scores recorded per sextant as suggested by Bartlett et al. 2008 [11]. Severity and treatment strategies were determined by two- indicators: 1) By risk levels (low, medium and high risk) with the BEWE sum cut-offs proposed by the same author [11], and 2) By the highest score reached per subject in at least one tooth $(\mathrm{BEWE}=1,2$ or 3$)$. To avoid any interpretation bias, the book from Lussi \& Jaeggi where the clinical use of BEWE index for dental erosion is graphically explained, was used as guidance during the entire study [12].

The presence of big restorations or appliances that did not allow, or compromised the quality of the scoring excluded the tooth. Moreover, buccal/ facial, occlusal, and lingual/palatal surfaces that presented tooth wear with a clear absence of acidic influence was scored as 0. Examples of this were pure attrition flat surfaces with correspondent antagonist, bruxism without any roundness or presence of cupping on occlusal surfaces, or pure abfraction on buccal surfaces and clear TW caused by foreign objects.

\section{Data management}

Data were analysed with the IBM SPSS v. 22.0 (SPSS Inc., Armonk, NY) software. In order to fulfil the aims, data analysis was done at three levels. First, an analysis was conducted for the entire young group of athletes with ID up to age 25 to identify the overall prevalence, severity and levels of risk with respect to ETW. Second, the Mann Whitney $U$ test was used to detect significant differences between the young athletes diagnosed with DS and the rest of the younger athletes with ID. Finally, in a third phase, athletes over the age of 25 diagnosed with DS together with the young athletes with DS were 
analysed in order to determine the presence of ETW in this specific group of athletes. For the entire analysis, Pearson Chi-square was used to detect significant differences among variables with a significance level of alpha $=0.05$.

\section{Results}

\section{Descriptive data}

A total of 723 athletes with ID participated in the SOSS program, Belgium 2016. From these, 232 (32.1\%; mean age $23.9 \pm 9.7$; age range 9-62 years old) fulfilled the inclusion criteria and were effectively recruited for the study. The final sample obtained for the young athletes with ID was 174, with $22.4 \%$ of them being athletes with DS $(n=39)$. The remaining 58 participants were adult athletes diagnosed with DS (Table 1). Age and gender did not show significant differences in the young group of athletes.

From all the participants in the SOSS program, only three refused dental examination due to anxiety reasons related with fear.

\section{ETW in young athletes with ID}

Overall, the prevalence of ETW (BEWE sum $>0$ ) for the young group of athletes with ID was $51.2 \%$ (Table 1).

Table 2 illustrates the ETW classification of athletes according to the highest severity reached in at least one tooth. Results indicate that $10.46 \%(n=18)$ of athletes were scored $\mathrm{BEWE}=3$.

Comparisons between young athletes with DS and those not having DS showed that mean BEWE sum scores $(p<0.005)$ and prevalence of ETW $(p<0.05)$ were significantly higher for young athletes with DS (Table 1 and Fig. 1).

Furthermore, a significantly higher percentage of athletes with DS were considered within the higher risk levels of ETW ( $<<0.05$; Fig. 2). The maximum BEWE sum reached was 17 in only one subject diagnosed with DS (age 19-year-old).
ETW in the group of young and adults athletes with DS The prevalence and mean BEWE sum of ETW for the group of athletes over age 25 with DS $(n=58)$ was 94.8\% (BEWE>0) and 6.83 (SD 4.6), respectively (Table 1). Only 3 subjects were free from ETW and the classification of the athletes according to the highest BEWE score reached showed that $34.5 \%$ had the most severe form in at least one tooth (Table 2).

\section{Discussion}

To the best of our knowledge, this is the first study evaluating the presence of ETW in athletes with ID participating at the SOSS. The main result of this study show that approximately one half of the athletes with ID up to age 25 who were screened in Belgium have at least one tooth surface affected by ETW (51.2\% BEWE sum $>0$ ). Moreover, $10.46 \%(n=18)$ of the athletes with ID had at least one tooth affected with the most severe form of ETW (BEWE $=3$ at tooth level) and $4.59 \%$ of them were considered at high risk (BEWE sum $>13$ ) according to the risk scale provided by Bartlett et al., 2008 [11].

The prevalence of ETW found in this study is within the range reported by several studies using BEWE index in young non-ID populations (between 15 to $79 \%$ BEWE sum $>0$ for 12 to 15 yr-olds) [13-19]. However, interestingly athletes with ID duplicated the percentage of severe forms of ETW when compared to general population, where often low severity rates are found [20, 21]. More precisely, the majority of the studies report that less than $5 \%$ of the subjects reach $\mathrm{BEWE}=3$ in at least one tooth (the most severe form) or that BEWE $=3$ scores are hardly found in the screened populations [16, 17, 21]. The fact that around $10 \%$ of the young athletes with ID in this study were in need of a restorative treatment due to ETW reasons differs clearly with the aforementioned data and may indicate that this group is at higher risk of ETW.

It appears that the athletes having DS are responsible for the higher severity of ETW found in this study (Table 1). Young athletes with DS have shown significantly more

Table 1 Prevalence of ETW and mean BEWE sum in Special Olympic athletes

\begin{tabular}{|c|c|c|c|c|c|c|c|}
\hline & & $\begin{array}{l}\text { Age } \\
\text { Mean } \pm S D\end{array}$ & $P$-value & $\begin{array}{l}\text { BEWE sum } \\
\text { Mean } \pm \text { SD }\end{array}$ & $P$-value & $\begin{array}{l}\text { ETW Prevalence } \\
\text { (BEWE sum }>0)\end{array}$ & $P$-value \\
\hline \multirow[t]{3}{*}{$\begin{array}{l}\text { Young Athletes with ID } \\
n=174\end{array}$} & $\begin{array}{l}\text { Athletes without DS } \\
n=135\end{array}$ & $\begin{array}{l}19.1 \pm 3.5 \\
\text { Age range (9-25) }\end{array}$ & \multirow[t]{3}{*}{0.39} & $1.96 \pm 3.47$ & $<0.005^{*}$ & $46.3 \%$ & \multirow[t]{5}{*}{$<0.05^{*}$} \\
\hline & $\begin{array}{l}\text { Athletes with DS } \\
n=39\end{array}$ & $\begin{array}{l}19.5 \pm 3.8 \\
\text { Age range (10-25) }\end{array}$ & & $4.67 \pm 5.64$ & & $69.2 \%$ & \\
\hline & Total & $19.3 \pm 3.5$ & & $2.52 \pm 4.04$ & & $51.2 \%$ & \\
\hline \multirow{2}{*}{$\begin{array}{l}\text { Older athletes with DS } \\
n=58\end{array}$} & & $37.7 \pm 8.9$ & & \multirow[t]{2}{*}{$6.83 \pm 4.57$} & & \multirow[t]{2}{*}{$94.8 \%$} & \\
\hline & & $\begin{array}{l}\text { Age range } \\
(26-62)\end{array}$ & & & & & \\
\hline
\end{tabular}

Comparative results were only performed between the young athletes with ID, which do not differ significantly in age. Mann-Whitney $u$ test was used at significance level of $p<0.05\left(^{*}\right)$ for comparisons between mean BEWE sum and Chi ${ }^{2}$ Test was used to compare prevalence of ETW ( $\left.p<0.05\right)$ 
Table 2 Distribution of Special Olympics athletes according to the highest BEWE score obtained

\begin{tabular}{llll}
\hline Criteria & $\begin{array}{l}\text { Young ID Athletes without DS } \\
n=135\end{array}$ & $\begin{array}{l}\text { Young ID Athletes with DS } \\
n=39\end{array}$ & $\begin{array}{l}\text { Older athletes with DS } \\
n=58\end{array}$ \\
\hline BEWE $=0$ & $72(53.33 \%)$ & $12(30.77 \%)$ & $3(5.17 \%)$ \\
BEWE $=1$ & $41(30.37 \%)$ & $12(30.77 \%)$ & $15(25.86 \%)$ \\
$B E W E=2$ & $10(7.40 \%)$ & $9(23.07 \%)$ & $20(34.48 \%)$ \\
BEWE $=3$ & $12(8.88 \%)$ & $6(15.38 \%)$ & $20(34.48 \%)$ \\
\hline
\end{tabular}

Athletes were distributed according the worst BEWE score obtained in at least one tooth

severe forms of ETW when compared with the young athletes with ID not having DS. Additionally, the older group of athletes with DS presented high prevalence rates (94.8\%) and severe forms of ETW, which differ considerably from the general population. This outcome is similar to the results shown by Bell et al. [7], where a group of people with DS had a significant higher index of TW (59.2\% pathological TW and $34.7 \%$ severe TW) in comparison to a control group. Nevertheless, caution should be taken at the moment to compare both studies since the present study specifically aimed to assess ETW.

Some medical and orofacial characteristics linked with DS patients may help explain the high severity of ETW found. These include among others the presence of reflux or GERD (Gastroesophageal Reflux Disease), use of medications that induce xerostomia, malocclusions, mouth breathing and a higher prevalence of bruxism [7, 22-24]. GERD has been several times recognized as risk factor for ETW [25], and in the case of DS literature suggests that around 13.8 to $59 \%$ of them suffer from this kind of gastric disorders [26]. It is possible that the combination between GERD and bruxism exacerbates the severity of ETW in these patients. This is consistent with the literature where it is suggested that TW processes do not occur in isolation and they are rather a result of multiple interactions [27]. This hypothesis may thus be accepted; however, the lack of evidence aiming to investigate the reasons behind the severe cases of ETW in DS patients indicates the need for further studies.

The results of this study should be interpreted within the limitations discussed in previous studies performed with SOSS populations. The sample obtained at SOSS events does not represent the entire population of people with ID for different reasons. This group of athletes with ID are well supported by their families and may receive frequent medical and dental care [28] and are very involved in sports. The exclusive selection of

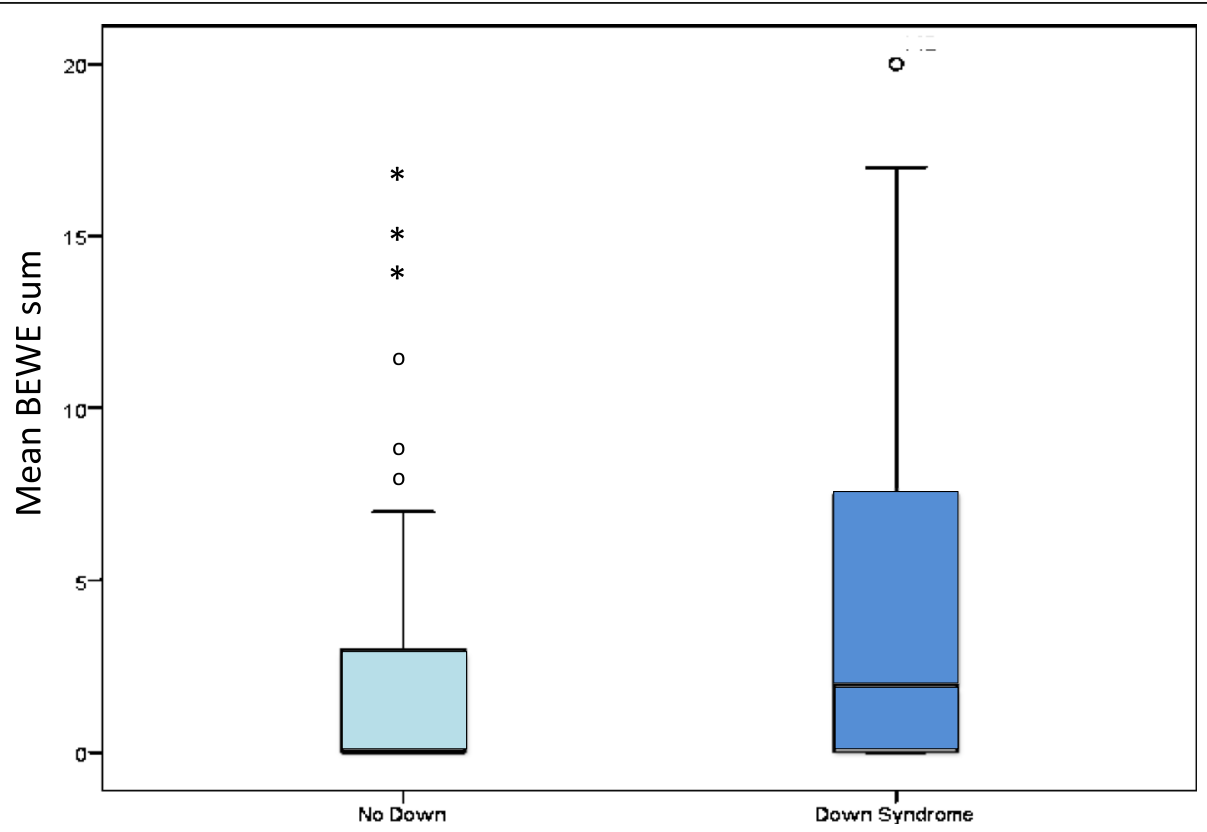

Fig. 1 Mean BEWE sum scores for young athletes with ID with and without Down syndrome (up to 25-year-old) 


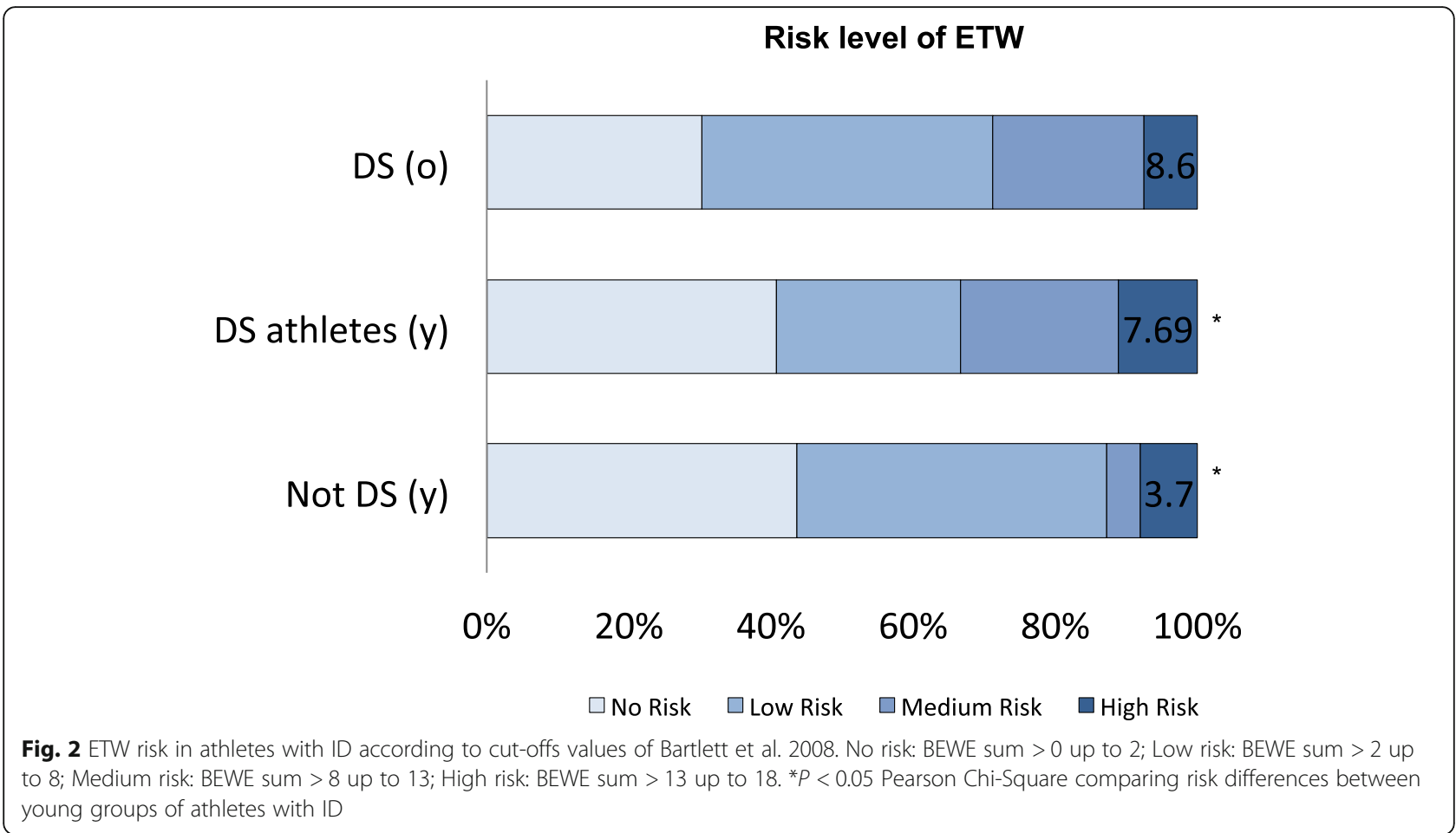

the younger group of athletes (up to 25 years of age) which, according to previous SOSS data, annually represents $26.9 \%(n=169)$ of the total number of athletes screened could be a bias [9]. On the other hand, the entire group of athletes with DS, was selected in order to obtain an idea of the oral status of this prevalent syndrome.

The study aimed to detect prevalence and severity of ETW to provide an idea of the oral status with respect to ETW in athletes with ID. Although the literature suggests that the application of questionnaires to assess the etiological factors is crucial for studies regarding ETW/ $\mathrm{TW}$, the detection of possible etiological factors through the use of a questionnaire was not performed, principally due to the different levels of comprehension related to the condition of the athletes with ID. Moreover, most of the athletes were accompanied by a trainer who is not well informed about the personal habits of the athlete. Questionnaires targeting caregivers could be useful for further elucidation of the potential aetiology of ETW in this population.

\section{Conclusions}

As a conclusion, half of the young athletes with ID presented at least one affected surface with ETW; however, the recorded prevalence and severity of ETW for the younger group of athletes with DS was distinctly higher than the athletes with ID not having DS. Furthermore, the severity reached by the DS group of athletes differs from the low severity of ETW commonly presented in the majority of the studies performed in general populations. This shows the need to generate knowledge with respect to aetiological factors involved in this specific population, in order to provide a correct management and prevention of ETW in populations with ID.

\section{Abbreviations}

BEWE: Basic erosive wear examination; DS: Down syndrome; ETW: Erosive tooth wear; ID: Intellectual disable; SO: Special Olympics; SOSS: Special Olympics special smiles program.; TW: Tooth wear

\section{Acknowledgements}

The authors thank the staff of the Special Olympics Healthy Athletes program.

\section{Funding}

The authors received no specific funding for this study.

\section{Availability of data and materials}

The dataset used and/or analysed during the current study is available from the corresponding author on reasonable request.

\section{Authors' contributions}

FM and CF carried out the cross-sectional study, FM drafted the manuscript and WJ performed the statistical analyses. FM, LM1, CF, LM2 and WJ participated in manuscript drafting and revision. FM, CF and LM2 participated in design and coordination of the study, All authors read and approved the final manuscript.

\section{Ethics approval and consent to participate}

Ethical approval was obtained from the local ethical committee of the Ghent University Hospital according to the "ICH Good Clinical Practice" of the declaration of Helsinki (2016/0461). Written inform consent from the athlete and/or the legal guardian was obtained. 


\section{Consent for publication}

Not applicable.

\section{Competing interests}

The authors declare that they have no competing interests.

\section{Publisher's Note}

Springer Nature remains neutral with regard to jurisdictional claims in published maps and institutional affiliations.

\section{Author details}

'Department of Paediatric Dentistry, PaeCoMeDis research cluster, Ghent University, Ghent, Belgium. ${ }^{2}$ Center of Special Care in Dentistry, PaeCoMeDiS, Ghent University, Ghent, Belgium. ${ }^{3}$ Oral Health Research Group ORHE, Faculty of Medicine and Pharmacy, Vrije Universiteit Brussel, Brussels, Belgium. ${ }^{4}$ Department of Educational Sciences EDWE-LOCl, Faculty of Psychology and Educational Sciences, VUB Vrije Universiteit Brussel, Brussels, Belgium. ${ }^{5}$ Department Paediatric Dentistry \& Special Care Dentistry, Dental School, Faculty of Medicine and Health sciences, University Gent, Gent, Belgium.

Received: 11 August 2017 Accepted: 20 February 2019

Published online: 28 February 2019

\section{References}

1. Carvalho TS, Colon P, Ganss C, Huysmans MC, Lussi A, Schlueter N, Schmalz $G$, Shellis RP, Tveit AB, Wiegand A. Consensus report of the European Federation of Conservative Dentistry: erosive tooth wear-diagnosis and management. Clin Oral Investig. 2015;19(7):1557-61.

2. Lussi A, Carvalho TS. Erosive tooth wear: a multifactorial condition of growing concern and increasing knowledge. Monogr Oral Sci. 2014;25:1-15.

3. Salas MM, Nascimento GG, Huysmans MC, Demarco FF: Estimated prevalence of erosive tooth wear in permanent teeth of children and adolescents: an epidemiological systematic review and meta-regression analysis. J Dent 2015, 43(1):42-50.

4. Bartlett DW, Lussi A, West NX, Bouchard P, Sanz M, Bourgeois D. Prevalence of tooth wear on buccal and lingual surfaces and possible risk factors in young European adults. J Dent. 2013;41(11):1007-13.

5. Saeves R, Espelid I, Storhaug K, Sandvik L, Nordgarden H. Severe tooth wear in Prader-Willi syndrome. A case-control study. BMC Oral Health. 2012;12:12.

6. Shellhart WC, Casamassimo PS, Hagerman RJ, Belanger GK. Oral findings in fragile X syndrome. Am J Med Genet. 1986;23(1-2):179-87.

7. Bell EJ, Kaidonis J, Townsend GC. Tooth wear in children with Down syndrome. Aust Dent J. 2002;47(1):30-5.

8. Marks L, Wong A, Perlman S, Shellard A, Fernandez C. Global oral health status of athletes with intellectual disabilities. Clin Oral Investig. 2018:22(4):1681-8

9. Fernandez C, Declerck D, Dedecker M, Marks L. Treatment needs and impact of oral health screening of athletes with intellectual disability in Belgium. BMC Oral Health. 2015;15:170.

10. Dellavia C, Allievi C, Pallavera A, Rosati R, Sforza C. Oral health conditions in Italian Special Olympics athletes. Spec Care Dentist. 2009;29(2):69-74.

11. Bartlett D, Ganss C, Lussi A: Basic erosive Wear examination (BEWE): a new scoring system for scientific and clinical needs. Clin Oral Investig 2008, 12 Suppl 1:S65-68.

12. Lussi J. Dental erosion: diagnosis, risk assessment, prevention. In: Treatment; 2011.

13. Zhang S, Chau AM, Lo EC, Chu CH. Dental caries and erosion status of 12-year-old Hong Kong children. BMC Public Health. 2014;14:7.

14. Vered Y, Lussi A, Zini A, Gleitman J, Sgan-Cohen HD. Dental erosive wear assessment among adolescents and adults utilizing the basic erosive wear examination (BEWE) scoring system. Clin Oral Investig. 2014;18(8):1985-90.

15. Muller-Bolla M, Courson F, Smail-Faugeron V, Bernardin T, Lupi-Pégurier L. Dental erosion in French adolescents. BMC Oral Health. 2015;15:147.

16. Alvarez Loureiro L, Fabruccini Fager A, Alves LS, Alvarez Vaz R, Maltz M. Erosive tooth wear among 12-year-old schoolchildren: a population-based cross-sectional study in Montevideo, Uruguay. Caries Res. 2015:49(3):216-25.

17. Alves LS, Brusius CD, Damé-Teixeira N, Maltz M, Susin C. Dental erosion among 12-year-old schoolchildren: a population-based cross-sectional study in South Brazil. Int Dent J. 2015;65(6):322-30.
18. Margaritis V, Mamai-Homata E, Koletsi-Kounari H, Polychronopoulou A Evaluation of three different scoring systems for dental erosion: a comparative study in adolescents. J Dent. 2011;39(1):88-93.

19. Provatenou E, Kaklamanos EG, Kevrekidou A, Kosma I, Kotsanos N. Erosive tooth Wear and related risk factors in 8- and 14-year-old Greek children. Caries Res. 2016;50(4):349-62.

20. Bartlett D. A personal perspective and update on erosive tooth wear - 10 years on: part 1 - diagnosis and prevention. Br Dent J. 2016;221(3):115-9.

21. Alaraudanjoki V, Laitala ML, Tjäderhane L, Pesonen P, Lussi A, Anttonen V. Association of erosive tooth wear and dental caries in northern Finland birth cohort 1966 - an epidemiological cross-sectional study. BMC Oral Health. 2016;17(1):6

22. Singh V, Arora R, Bhayya D, Singh D, Sarvaiya B, Mehta D. Comparison of relationship between salivary electrolyte levels and dental caries in children with Down syndrome. J Nat Sci Biol Med. 2015;6(1):144-8.

23. Deps TD, Angelo GL, Martins CC, Paiva SM, Pordeus IA, Borges-Oliveira AC. Association between dental caries and Down syndrome: a systematic review and meta-analysis. PLoS One. 2015;10(6):e0127484

24. Bauer D, Evans CA, Begole EA, Salzmann L. Severity of occlusal disharmonies in Down syndrome. Int J Dent. 2012;2012:872367.

25. Schlueter $N$, Tveit AB. Prevalence of erosive tooth wear in risk groups. Monogr Oral Sci. 2014;25:74-98.

26. Abanto J, Ciamponi AL, Francischini E, Murakami C, de Rezende NP, Gallottini M. Medical problems and oral care of patients with Down syndrome: a literature review. Spec Care Dentist. 2011;31(6):197-203.

27. Shellis RP, Addy M. The interactions between attrition, abrasion and erosion in tooth wear. Monogr Oral Sci. 2014;25:32-45

28. Feldman CA, Giniger M, Sanders M, Saporito R, Zohn HK, Perlman SP. Special Olympics, special smiles: assessing the. feasibility of epidemiologic data collection J Am Dent Assoc. 1997;128(12):1687-96.

Ready to submit your research? Choose BMC and benefit from

- fast, convenient online submission

- thorough peer review by experienced researchers in your field

- rapid publication on acceptance

- support for research data, including large and complex data types

- gold Open Access which fosters wider collaboration and increased citations

- maximum visibility for your research: over $100 \mathrm{M}$ website views per year

At $\mathrm{BMC}$, research is always in progress.

Learn more biomedcentral.com/submissions 